JMI Vol. 41 No. 1, Juni 2019

METAL INDONESIA

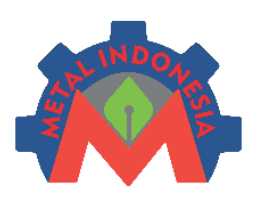

http://www.jurnalmetal.or.id/index.php/jmi

p-issn: 0126-3463

e-issn: 2548-673X

\title{
PERBAIKAN KUALITAS PRODUK PADA INDUSTRI PEMBUAT KOMPONEN LOGAM DENGAN PENERAPAN METODE $Q C C$
}

\section{IMPROVING QUALITY PRODUCT ON THE METAL COMPONENTS MANUFACTURING INDUSTRIES USING QCC METHOD}

\author{
Hafid Abdullah $^{1}$ dan Taisuke Nishida ${ }^{2}$ \\ ${ }^{1}$ Balai Besar Logam dan Mesin (BBLM), Kementerian Perindustrian \\ ${ }^{2}$ JICA Expert on Production Management \\ Jl. Sangkuriang No. 12 Bandung 40135 \\ Email: hafidochan@yahoo.com
}

\begin{abstract}
Abstrak
Makalah ini menyajikan hasil penelitian analisis perbaikan kualitas produk pada industri pembuat komponen logam melalui penerapan metode QCC. Tujuannya adalah meningkatkan kualitas produk logam agar dapat memuaskan konsumen (mitra usahanya) sehingga mampu bersaing di pasar global. Dalam penelitian ini, diberikan contoh kasus implementasi QCC di salah satu industri pendukung pembuat komponen alat berat di Indonesia. Cara peningkatan melalui implementasi manajemen QCC (Quality Control Circle) untuk penanggulangan perbaikan yang berkesinambungan. Hasil implementasi QCC di PT. MTM adalah perbaikan kualitas produk spacer karena komponen tersebut mempunyai rasio kerusakan paling tinggi yang di klaim PT. Komatsu Indonesia sebagai konsumen (mitra usahanya) sehingga menjadi prioritas utama ditanggulangi. Hasil perbaikan adalah presentasi rasio cacat komponen spacer sekitar $25 \%$ (sebelum perbaikan) dan dapat diturunkan menjadi 0\% (setelah perbaikan).
\end{abstract}

Kata kunci: QCC, 5W1H, industri penunjang.

\begin{abstract}
This paper presents the results of research the analysis of improvement quality products on the metal components manufacturing industries by using QCC method. The target of this research is to enhance production quality in order to fulfill customer satisfaction (partnership) to compete in a global market. In this research, and example taken is a case of QCC implementation at one of the supporting industries for heavy componets manufacturing in Indonesia. The research was improved way throught the implementation of the QCC (Quality Control Circle) management for continuous improvement. Result of the implementation QCC in PT. MTM is a spacer product quality improvement because it has the highest reject ratio claimed by PT. Komatsu Indonesia as its customer (partnership) so that the main priority is countermeasured. Result of the improvement the percentage of rejected ratios spacer component is $25 \%$ (before improvement) and can be decreased to be $0 \%$ (after improvement).
\end{abstract}

Keywords: QCC, $5 W+1 H$, supporting industries. 


\section{PENDAHULUAN}

Pembangunan industri nasional yang merupakan bagian dari proses industrialisasi menjadi tantangan bagi semua sektor industri untuk bersaing ketat, terutama dalam menghadapi era globalisasi. Tantangan eksternal yang harus dihadapi adalah Indonesia sebagai anggota organisasi perdagangan bebas dunia (WTO) adalah pasar dalam negeri terbuka untuk masyarakat ekonomi ASEAN (MEA) dengan Cina yang disebut dengan ASEAN-China Free Trade Agreement (ACFTA) dan APEC pada tahun 2020. Hal ini berdampak pada meningkatnya peluang ekspor sekaligus ancaman bagi industri-industri penunjang (supporting industries) di dalam negeri dari munculnya produk-produk impor dalam jumlah banyak yang jauh lebih berkualitas dengan harga yang sangat bersaing (Hafid Abdullah 2012).

Industri penunjang menurut GAIKINDO (Gabungan Industri Kendaraan Bermotor Indonesia) adalah industri-industri pembuat komponen dan parts untuk memenuhi kebutuhan industri lain untuk mendukung pembuatan akhir atau sebagai komponen/part after market. (Achadiat Atmawinata 2008)

Peranannya yang sangat penting dalam menunjang pengembangan industri di Indonesia, dapat mendorong laju pembangunan ekonomi daerah karena bisa memberikan rangsangan bagi sektor-sektor industri lainnya baik yang terkait secara langsung maupun tidak langsung melalui efek penggandaan atau multiplier effect (Hafid 2015). Lokasinya tersebar di DKI Jakarta, Jawa Barat (Tangerang, Bekasi, Bogor, Karawang, Sukabumi, Bandung), Jawa Tengah (Tegal, Klaten, Juwana) dan Jawa Timur (Sidoardjo, Pasuruan, Surabaya) dan sebagian ada di Medan (MIDC 2012). Dilihat dari skala industrinya sangat beragam mulai dari industri kecil menengah (IKM) sampai perusahaan berskala besar dengan jaringan permodalan dan pemasaran internasional. Industri berskala besar umumnya adalah perusahaan PMA atau perusahaan joint venture sedangkan industri kecil menengah (IKM) umumnya perusahaan lokal (PMDN).

Dalam usaha meningkatkan mutu, produktivitas (APO 2015) dan daya saing daya saing suatu perusahaan di pasar bebas (Schwab 2017), khususnya industri penunjang berskala IKM agar bisa bertahan dan menang dalam persaingan kuncinya adalah harus dapat meningkatkan produktivitas dan menjaga mutu produk yang akan dipasarkannya. Kondisi ini mensyaratkan usaha yang optimal dari suatu sistem industri (Riggs 2007)(Richard B. Chase, F. Robert Jacobs 2004) (Perindustrian 2014), yaitu adanya pengendalian mutu (quality control) di setiap tahapan proses produksi, mulai dari masukan bahan baku sampai keluaran produk jadi (Astra 2010)(Sambas 2014), agar dapat memuaskan konsumen maupun yang mengerjakannya.

Menurut Michael E. Porter (Wirasasmita 2013) persaingan industri dipengaruhi beberapa faktor, yaitu: (1) rivalitas diantara para pelaku bisnis yang sama, (2) ancaman pendatang baru, (3) ancaman pemasok, (4) ancaman barang pengganti, (5) ancaman pembeli. Apabila ancaman-ancaman dan rivalitas di dalam sangat tinggi, keadaan tersebut akan mempengaruhi profitabilitas.

Salah satu cara untuk meningkatkan keunggulan daya saing perusahaan adalah dengan penerapan sistem manajemen Total Quality Control (TQC) yang dalam pelaksanaannya dilakukan dengan Quality Control Circle (QCC)nya. Untuk menghasilkan suatu usulan perbaikan yang berkesinambungan (Jeffey K. Liker 2007) adalah melalui cara peningkatan kualitas dan produktivitas hasil produksi yang dapat memuaskan konsumen dan mampu meningkatkan daya saing, baik di pasar domestik maupun di pasar global.

Pengendalian Mutu Terpadu (Total Quality Control (PMT/TQC) adalah suatu sistem manajemen yang mengikut sertakan seluruh pimpinan dan karyawan dari semua tingkatan dengan menerapkan konsepsi pengendalian kualitas dengan metode statistik untuk meningkatkan kepuasan pelanggan dan yang mengerjakannya (Astra 2010).

Manajemen Quality Control Circle (QCC) didefinisikan sebagai daya upaya untuk mengendalikan kegiatan QCC sehingga menunjang rencana kegiatan perusahaan. Sedangkan yang dimaksud dengan QCC adalah kelompok kecil karyawan/organisasi (4-10 orang) dari pekerjaan yang sejenis yang secara sukarela mengadakan pertemuan teratur diluar jam kerjanya untuk melakukan perbaikan-perbaikan 
metode kerja dan kualitas produk di tempat kerja (Ishikawa 2005)(Ueso 2011).

Berdasarkan permasalahan tersebut, maka tujuan penelitian yang ingin dicapai adalah meningkatkan kualitas hasil produksi pada industri pembuat komponen logam agar dapat memuaskan konsumennya sehingga mampu bersaing di pasar global. Cara peningkatannya adalah melalui implementasi manajemen QCC untuk penanggulangan perbaikan yang berkesinambungan. Adapun contoh kasusnya dilakukan di PT. MTM yang merupakan salah satu industri pendukung pembuat komponen alat berat di Indonesia.

Pada Gambar 1, diperlihatkan komponen spacer hasil produksi PT. MTM yang sering di klaim oleh PT. Komatsu Indonesia sebagai mitra usahanya karena komponen tersebut mempunyai rasio kerusakan paling tinggi sehingga menjadi prioritas utama ditanggulangi.

Diharapkan hasil penelitian ini dapat berguna bagi para pembina maupun pemilik atau manajemen perusahaan lain di Indonesia dalam mendorong pengembangan usahanya yang lebih maju di masa depan.

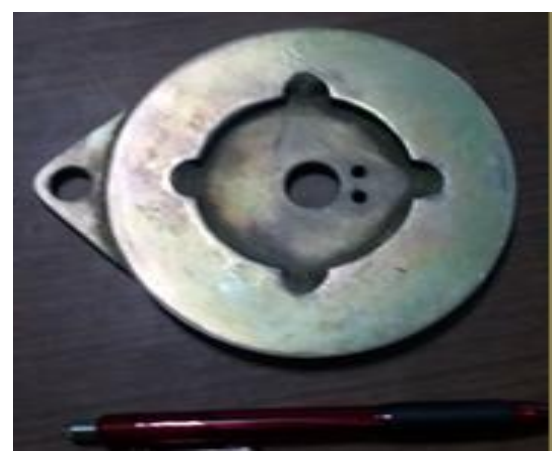

Gambar 1. Komponen spacer hasil produksi PT. MTM

\section{METODOLOGI}

Metode penelitian ini menggunakan metode studi kasus yang berkonsentrasi pada analisis historis, deskriptif dan tindakan. Penelitian historis diperoleh dengan cara mengumpulkan, memeriksan dan mengevaluasi proses dan hasil produksi komponen logam yang dibuat PT. MTM. Sedangkan penelitian deskriptif bertujuan untuk mengetahui akar penyebab terjadinya kerusakan komponen spacer. Selanjutnya dengan penelitian tindakan diharapkan dapat diketahui dan ditanggulangi penyebabnya sehingga kualitas dan produktivitas dapat lebih ditingkatkan lagi melalui upaya pengembangan kemampuan dan ketrampilan para karyawannya.

Penelitian ini dilakukan pada periode bulan April s/d Nopember 2016. melalui kegiatan bimbingan teknis dan konsultasi pada Project on Enhancement of Metal Working for Supporting Industries of Construction Machinery in Indonesia, bekerjasama BBLM dengan JICA Jepang.

Beberapa pendekatan yang digunakan untuk pengambilan data primer dan sekunder adalah melalui implementasi metode QCC di PT. MTM, yaitu melalui survey industri dengan melakukan observasi dan wawancara secara langsung kepada manajemen perusahaan yang menjadi objek penelitian selain itu hearing dengan para teknisi dan tenaga ahli JICA Sedangkan data sekunder diperoleh dari studi literatur dari berbagai terbitan, jurnal-jurnal dan laporan institusi yang berkaitan dengan pembahasan, dll.

Untuk mengetahui pengendalian mutu secara terpadu terhadap kualitas produk pada industri komponen logam dilakukan penerapan sistem manajemen $Q C C$ dengan contoh kasus di PT. MTM. Untuk menjaga kerahasiaan nama perusahaan tersebut hanya disebutkan inisialnya.

Tahapan kegiatan implementasi QCC di PT. MTM adalah sebagai berikut:

1. Persiapan komite QCC, struktur organisasi dan program kerja.

2. Pencanangan (kick of) kegiatan implementasi metode QCC.

3. Sosialisasi program kerja kegiatan komite TQC/QCC: (a) pembentukan tim QCC, (b) penyusunan jadwal pertemuan tim QCC (c) diklat/bimbingan implementasi.

4. Survey industri dan memulai kegiatan tim QCC di PT. MTM, yang meliputi: (a) identifikasi kondisi perusahaan sebelum perbaikan, (b) pengamatan aliran proses pembuatan produk, (c) mendokumentasi kondisi awal sebelum dan sesudah perbaikan, (d) meneliti faktor-faktor penyebab cacat produk dilihat dari, yaitu: bahan/material, produk jadi, operator, mesin dan peralatan, metode kerja dan lingkungan kerja. 
5. Konsultasi, evaluasi dan rencana penanggulangannya.

6. Pengambilan foto setelah perbaikan.

7. Standarisasi dan rencana penanggulangan berikutnya.

8. Kesimpulan dan rekomendasi hasil penelitian.

9. Presentasi hasil kegiatan oleh tim QCC di depan pimpinan dan karyawan perusahaan.

10.Evaluasi dan pembuatan laporan penelitian.

Tahapan penelitian yang dilakukan menurut (Nazir 2011) adalah sebagai berikut:

1. Identifikasi dan pemilihan masalah.

2. Pemilihan kerangka konseptual untuk masalah penelitian serta hubunganhubungan dengan penelitian sebelumnya.

3. Memformulasikan masalah penelitian.

4. Membangun penyelidikan.

5. Memberikan definisi terhadap pengukuran variabel.

6. Memilih prosedur dan teknik sampling yang digunakan (Sugiono 2008)(Darmawan 2004).

7. Pengumpulan dan pengolahan data.

8. Menganalisis dan interpretasi data.

9. Kesimpulan dan saran

10. Pelaporan hasil penelitian.

\section{HASIL DAN PEMBAHASAN}

Persoalan-persoalan perbaikan (improvement) dengan penyelesaian melalui metode $Q C C$ biasanya sederhana yang tidak dapat terlihat oleh para manajer (pemilik) perusahaan. Tetapi dapat diketahui dan ditanggulangi oleh para operator di tempat kerjanya.

Sebagai contoh kasus perbaikan mutu produk logam pada industri pembuat komponen logam adalah dilakukan di bagian produksi PT. MTM yang berlokasi di LIK Takaru Tegal Jawa Tengah. Perusahaan ini memiliki jenis usaha fabrikasi sheet metal working komponen alat berat (Gambar 2). Saat ini perusahaan memfokuskan pada pelanggan domestik. Beberapa konsumennya adalah PT. Komatsu Indonesia (pelanggan utama), PT. Katsushiro dan PT. Hanken.

Kebijakan mutu perusahaan adalah: (1) memenuhi kepuasan pelanggan yang menjadi mitra usahanya, (2) tetap menjaga target kualitas dan produktivitas, (3) memberikan kualitas yang terbaik.

Dalam menghadapi persaingan global, maka perusahaan menyadari perlunya peningkatan mutu dan produktivitas. Oleh karena itu perusahaan memutuskan untuk mendapat bimbingan dan konsultansi TQC/QCC dari penulis sebagai counterpart tenaga ahli JICA pada Project on Enhancement of Metal Working for Supporting Industries of Construction Machinery in Indonesia.

Langkah-langkah pengendalian kualitas yang dilakukan dengan metode QCC (Komatsu, 2015). adalah sebagai berikut:

1. Langkah I. Pemilihan Tema

a. Tema: "Perbaikan kualitas hasil produksi PC 130-F"

b. Judul: "Menurunkan reject ratio komponen spacer 2075465260 di proses drilling"

c. Alasan pemilihan tema :

- Berdasarkan hasil inspeksi yang dilakukan dibagian produksi PT. MTM masih banyak komponen spacer yang di klaim PT. Komatsu

- Meningkatkan kualitas hasil produksi PT. MTM sebagai upaya bagi kepuasan PT. Komatsu yang menjadi konsumen atau mitra usahanya. 


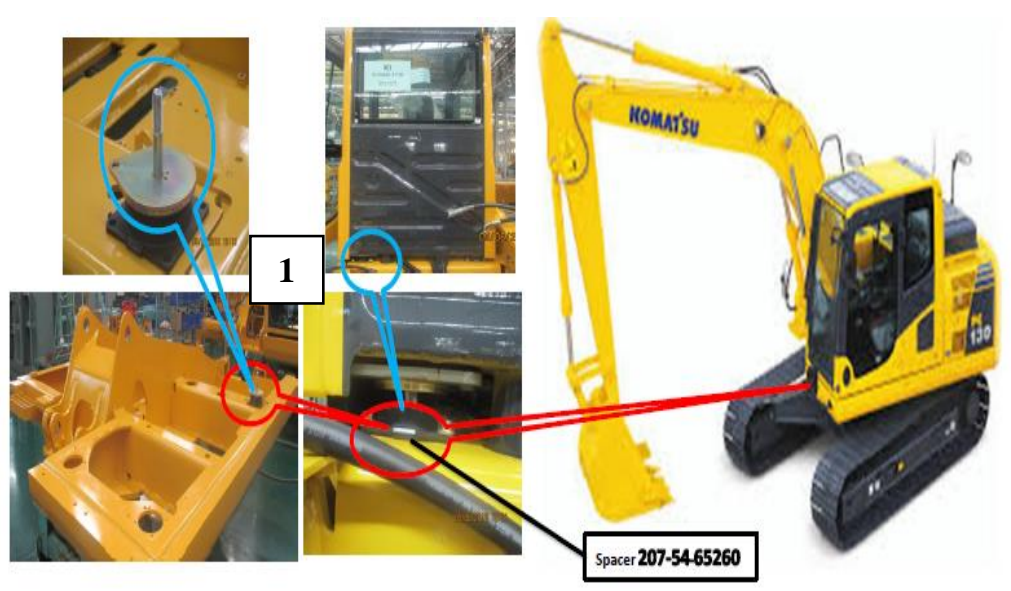

Keterangan:

1. Komponen spacer

Gambar 2. Hydraulic excavator PT. Komatsu Indonesia

2. Langkah II: Mengetahui kondisi saat ini dan menentukan target

Berdasarkan pemeriksaan terhadap data jenis komponen spacer hasil produksi tahun 2016 dibagian produksi PT. MTM yang dibuat untuk pesanan PT. Komatsu Indonesia, diketahui komponen spacer 2075465260

(Gambar 1) mempunyai reject ratio (25\%) tertinggi yang di klaim PT. Komatsu seperti ditunjukkan pada Gambar 3 dan Gambar 4. Hal ini menunjukkan bahwa komponen tersebut perlu mendapat prioritas utama untuk ditanggulangi. Selanjutnya team QCC PT. MTM menetapkan target rasio reject menjadi $0 \%$ klaim

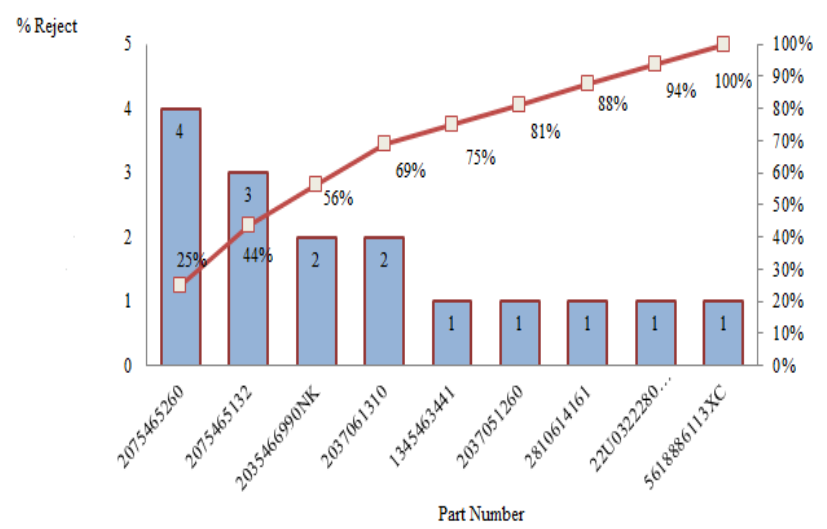

Gambar 3. Komponen spacer produksi PT. MTM yang diklaim

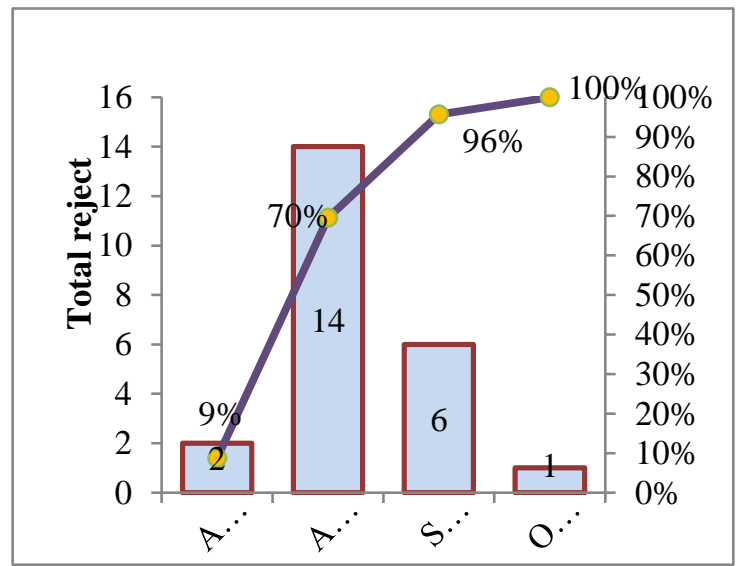

Gambar 4. Rasio reject komponen spacer tahun 2016 di PT. MTM

3. Langkah III: Rencana aktivitas

Setelah dibentuk tim QCC yang terdiri dari group kecil (small group activities) dengan jumlah anggota 6 orang, dilengkapi ketua kelompok, fasilitator dan advisor masingmasing 1 orang, maka dibuatlah jadwal program aplikasi metode QCC seperti ditunjukkan pada Tabel 1.

4. Langkah IV: Analisis penyebab masalah Untuk mengetahui penyebab masalah kerusakan produk kondisi saat ini terlebih dahulu dibuat aliran proses produksi pembuatan spacer di PT. MTM, seperti ditunjukkan pada Gambar 5. Dari Gambar 3 dan Gambar 4 terlihat bahwa komponen spacer menjadi adalah penyebab kerusakan 
tertinggi sehingga perlu segera ditanggulangi. Penyebab kerusakan di analisis kembali dengan menggunakan fish bone yang mencakup 5M (material, mesin dan peralatan, manusia, metode kerja dan lingkungan kerja). Melalui diskusi team QCC penyebab utama kerusakan adalah karena teknisi PT. MTM menggunakan mal untuk menandai spacer yang akan di proses drilling. Setelah dipergunakan beberapa lama dan berjalannya waktu, maka lobang pada mal semakin membesar, sehingga waktu proses mal posisinya tidak di tengah (center).

Dalam suatu proses produksi drilling(Gambar 6) dapat terjadi adanya dispersi kualitas produk, oleh karena itu untuk menganalisis penyebab terjadinya masalah sebab akibat yang berpengaruh terhadap kualitas komponen spacer tersebut, digunakan metode branstorming bersama anggota team QCC (Tabel 2).

5. Langkah V: Melaksanakan perbaikan Setelah mengetahui akar permasalahan dengan menggunakan metoda analisis sebab akibat kemudian ditentukan cara-cara penanggulangan reject komponen spacer 2075465260 melalui diskusi dalam kelompok QCC, diupayakan dapat menghilangkan atau mengurangi kerusakan yang terjadi.

Peningkatan kualitas produk dapat dicapai salah satunya dengan menggunakan alat bantu (jig drill) terhadap proses produksi (Gambar 7). Ketidakpresisian disebabkan posisi dan ukuran lubang tengah tidak berada ditengah karena penggunaan mesin bor manual. Kondisi ini menyebabkan longgar. Salah satu upaya yang dapat dilakukan untuk memperbaikinya adalah dengan menggunakan alat bantu (jig drill).

Penggunaan jig drill membantu teknisi/operator dalam memposisikan pada posisi yang tepat, sehingga kualitas dan produktivitas spacer dapat meningkat.

Langkah selanjutnya ialah melaksanakan perbaikan dengan menggunakan metode $5 \mathrm{~W}+$ 1H (What, Why, Where, Who, When, How) dapat di lihat pada Tabel 3.

Tabel 1. Jadwal kegiatan team QCC di PT. MTM (Nopember ke Desember 2016)

\begin{tabular}{|c|c|c|c|c|c|c|c|c|c|c|c|c|}
\hline \multicolumn{3}{|c|}{ Jadwal Aktivitas (Rencana dan Realisasi) } & \multicolumn{10}{|c|}{ Aktivitas QCC 2016} \\
\hline \multirow{2}{*}{\multicolumn{3}{|c|}{ Langkah perbaikan }} & \multicolumn{10}{|c|}{ Minggu } \\
\hline & & & 1 & 2 & 3 & 4 & 5 & 6 & 7 & 8 & 9 & 10 \\
\hline \multirow{4}{*}{ Plan } & 1. & Memilih tema dan judul & $\mathbf{x}$ & & & & & & & & & \\
\hline & 2. & $\begin{array}{l}\text { Mengetahui kondisi saat ini dan } \\
\text { menetapkan target }\end{array}$ & $\mathbf{x}$ & $\mathbf{x}$ & $\mathbf{x}$ & $\mathbf{x}$ & & & & & & \\
\hline & 3 & Membuat rencana aktivitas & $\mathbf{x}$ & $\mathbf{x}$ & & & & & & & & \\
\hline & 4 & Analisis penyebab masalah & & & $\bar{x}$ & $\bar{x}$ & $\bar{x}$ & $\bar{x}$ & & & & \\
\hline Do & 5 & Melakanakan rencana perbaikan & & & & & & & & & & \\
\hline Check & 6 & Evauasi hasil dari rencana perbaikan & & & & & & & $\bar{x}$ & $\overline{\mathbf{x}}$ & & \\
\hline \multirow{2}{*}{ Action } & 7 & Membuat standarisasi & & & & & & & & & $\mathbf{x}$ & \\
\hline & 8 & Merencanakan rencana selanjutnya & & & & & & & & & & $\mathbf{x}$ \\
\hline
\end{tabular}

Catatan : $\mathbf{x}=$ rencana sesuai realisasi

Tabel 2. Analisis penyebab masalah

\begin{tabular}{|c|c|c|c|c|}
\hline Faktor & Why 1 & Why 2 & Why 3 & Why 4 \\
\hline Metode & $\begin{array}{l}\text { Sudah ada metode } \\
\text { tapi belum optimal } \\
\text { dilaksanakan work } \\
\text { instruction di } \\
\text { mesin drilling. }\end{array}$ & $\begin{array}{l}\text { Banyak reject } \\
\text { komponen } \\
2075465260\end{array}$ & $\begin{array}{l}\text { Pada check sheet } \\
\text { terlihat berbagai jenis } \\
\text { reject }\end{array}$ & $\begin{array}{lr}\text { Hasil pekerjaan operator } \\
\text { baru berbeda } \\
\text { yang } & \text { tengan } \\
\text { berpengalaman } & \end{array}$ \\
\hline Operator & $\begin{array}{l}\text { Dimensi antar hole } \\
\text { NG }\end{array}$ & $\begin{array}{lr}\text { Saat } & \text { proses } \\
\text { marking } & \text { dengan } \\
\text { mal tidak center }\end{array}$ & $\begin{array}{l}\text { Mal marking sudah } \\
\text { tidak standar }\end{array}$ & $\begin{array}{l}\text { Titik hole pada mal } \\
\text { marking sudah membesar }\end{array}$ \\
\hline
\end{tabular}




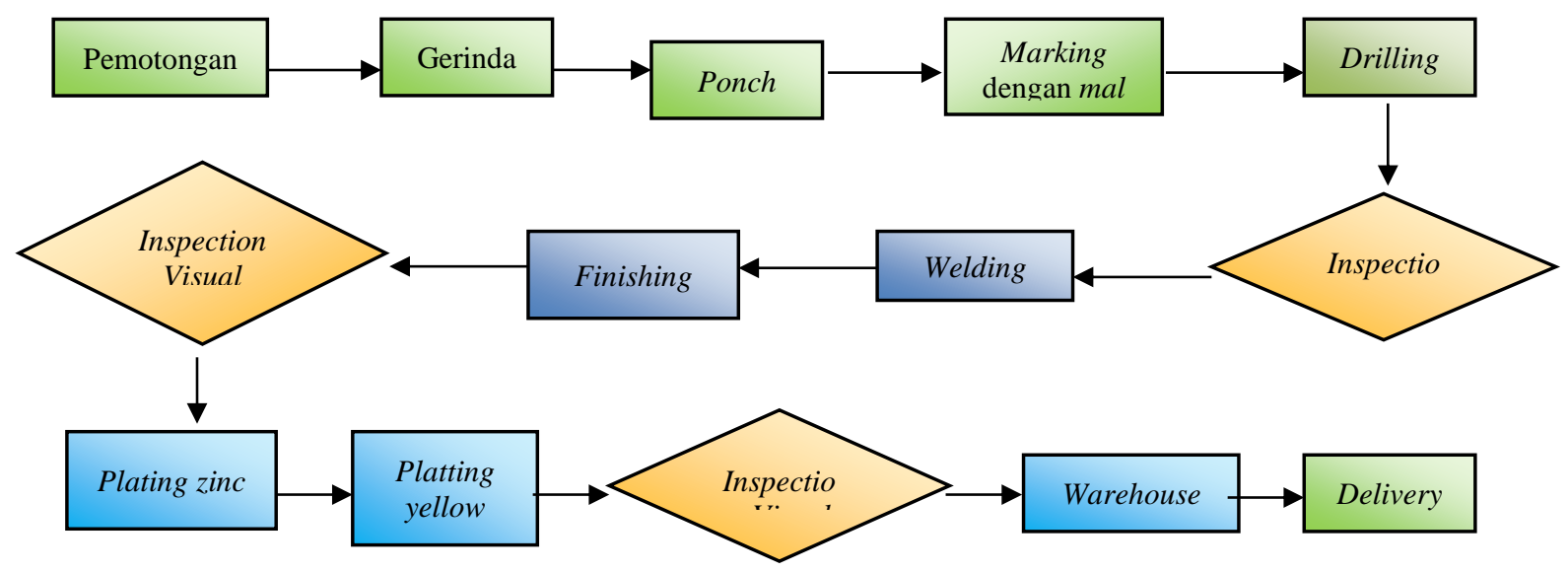

Gambar 5. Proses pembuatan komponen spacer di PT. MTM
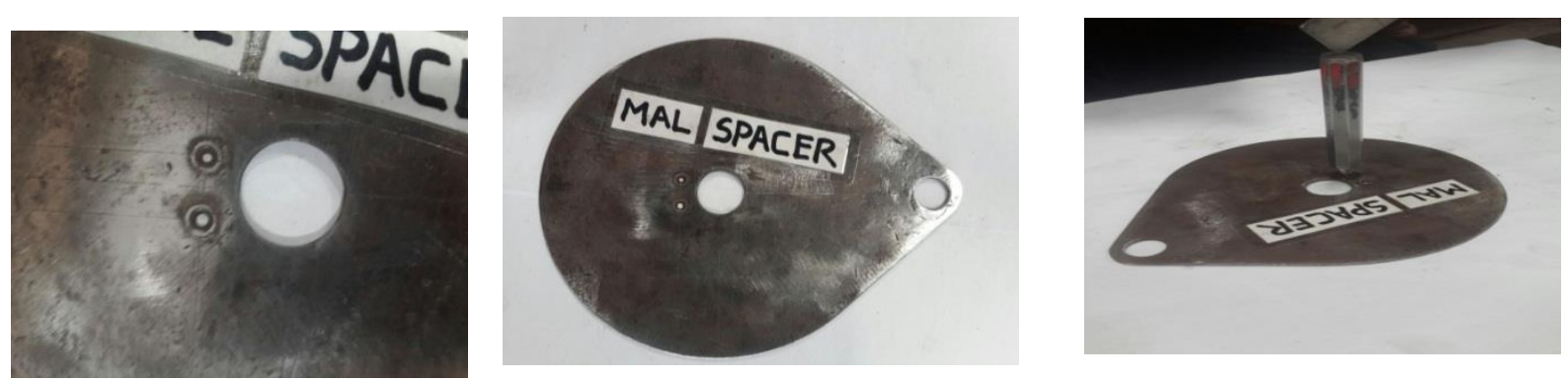

Gambar 6. Proses drilling menggunakan mal (sebelum perbaikan)

Tabel 3. $5 \mathrm{~W}+1 \mathrm{H}$

\begin{tabular}{|c|c|c|c|c|c|}
\hline $\begin{array}{l}\text { What } \\
\text { (Apa) }\end{array}$ & $\begin{array}{c}\text { How } \\
\text { (Bagaimana) }\end{array}$ & $\begin{array}{c}\text { Why } \\
\text { (Mengapa) }\end{array}$ & $\begin{array}{c}\text { Where } \\
\text { (Dimana) }\end{array}$ & $\begin{array}{l}\text { Who } \\
\text { (Siapa) }\end{array}$ & $\begin{array}{c}\text { When } \\
\text { (Kapan) }\end{array}$ \\
\hline $\begin{array}{lr}\text { Alat mal } \\
\text { making diganti } \\
\text { dengan jig } \\
\text { drill }\end{array}$ & $\begin{array}{l}\text { Buat jig drill \& } \\
\text { jig inspection }\end{array}$ & $\begin{array}{l}\text { - Mempercepat } \\
\text { proses produksi } \\
\text { dan menghindari } \\
\text { marking yang tidak } \\
\text { standar. } \\
\text { - Mempercepat } \\
\text { proses pengecekan } \\
\text { dan mengganti } \\
\text { produk }\end{array}$ & Area drilling & $\begin{array}{l}\text { 1. Irfan } \\
\text { 2. Joko } \\
\text { 3. Eko S } \\
\text { 4. Eko W. }\end{array}$ & 1 Nopember 2016 \\
\hline
\end{tabular}
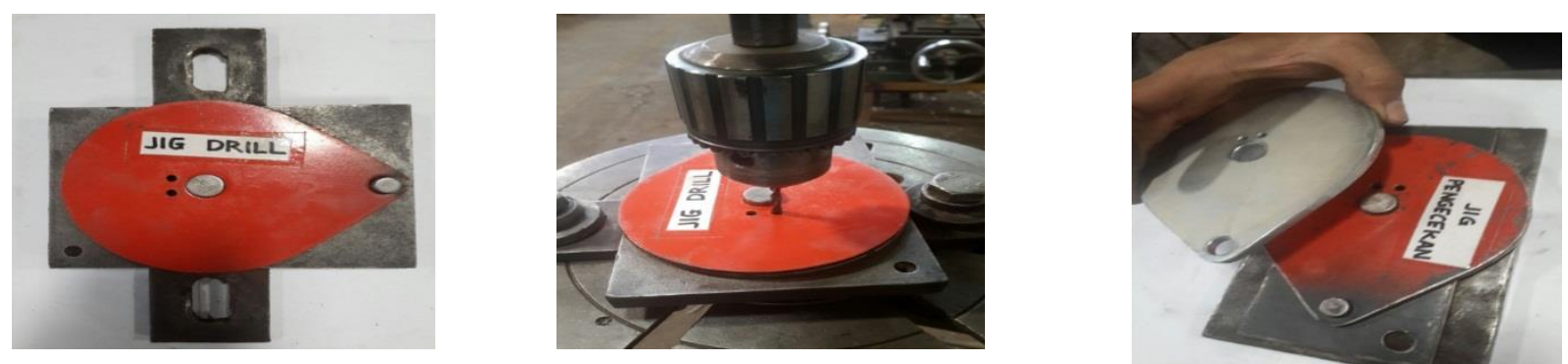

Gambar 7. Proses drilling menggunakan jig (setelah perbaikan) 
6). Langkah VI : Evaluasi hasil perbaikan

Evaluasi hasil perbaikan dapat dibandingkan dengan kondisi sebelum dan sesudah penerapan QCC yang dapat dilihat pada Gambar 8. Dari gambar tersebut terlihat bahwa prosentasi reject rasio komponen spacer sebesar 25\% (sebelum perbaikan) sehingga perlu diperbaiki. Setelah dilakukan pengendalian mutu, hasilnya diperoleh penurunan dan reject rasio menjadi $0 \%$ (setelah perbaikan).

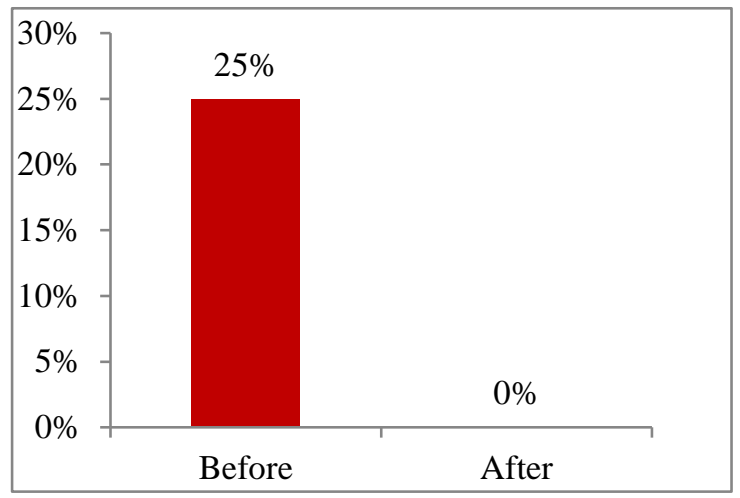

Gambar 8. Hasil usaha perbaikan kualitas komponen spacer

7. Langkah VII: Standarisasi

Untuk memperlihatkan keberhasilan kelompok QCC dalam menurunkan tingkat kerusakan komponen spacer yang diproduksi, maka:

a. Melaksanakan peningkatan pengetahuan dan keterampilan dibagian permesinan, supervisor/mandor.

b. Pengendalian QC menggunakan jig pengecekan setelah proses drilling.

c. Melaksanakan prevententive maintenance terhadap mesin dan peralatan

d. Melaksanakan monitoring pencegahan penyimpangan secara terus menerus dengan mengikuti langkah-langkah perbaikan serta meneliti faktor-faktor lainnya yang masih timbul, sehingga faktor penyimpangan kualitas produk dapat ditekan secara optimal.

8. Langkah VIII: Rencana berikutnya Membahas tema perbaikan proses, produk atau komponen lainnya yang timbul berdasarkan skala prioritas. Keuntungan yang didapat oleh PT. MTM dengan adanya QCC adalah manajer dan supervisor terlepas dari pekerjaan-pekerjaan rutin yang memenuhi jadwal mereka. Keputusan-keputusan yang semula membutuhkan persetujuan manajemen dapat diberikan kepada para supervisor atau foreman. Keputusan-keputusan yang dibuat ditingkat bawah adalah memang yang seharusnya di buat di sana.

QCC telah berhasil mengantarkan sukses dalam meningkatkan kualitas hasil produksi komponen spacer di unit produksi PT. MTM. Sehingga tim QCC telah membawa keuntungan yang sebesar-besarnya baik itu bagi karyawan maupun perusahaan.

Perusahaan yang sukses dalam mengimplementasikan QCC adalah perusahaanperusahaan yang konsisten dalam melakukan kegiatan-kegiatan memberikan saran sampai hal itu menjadi suatu bagian dari kebudayaan perusahaan. Sistem itu sendiri tidak harus dari awal sudah sempurna. Yang penting adalah antusiasme dari para manajer dan penyelia, karena hal itu akan menutupi kekurangan dalam sistem yang sudah ada.

\section{KESIMPULAN}

Berdasarkan hasil analisis yang telah dilakukan, maka didapat beberapa kesimpulan dan saran sebagai berikut. Rendahnya kualitas produk pada industri pembuat komponen logam dapat ditingkatkan melalui implementasi Quality Control Circle (QCC). Berdasarkan hasil implementasi metode QCC di PT. MTM dapat diperbaiki prosentase komponen spacer yang diafkir (reject ratio) dan di klaim oleh PT. Komatsu Indonesia, yaitu dari $25 \%$ (sebelum perbaikan) turun menjadi 0\% (setelah perbaikan). Hasil yang telah dicapai oleh PT. MTM dapat dijadikan sebagai contoh kasus bagi para pengelola maupun pembina perusahaan lainnya untuk pengembangan usaha industri pembuat komponen logam (supporting industries) di dalam negeri di masa datang.

\section{UCAPAN TERIMA KASIH}

Makalah ini dibuat tidak semata-mata merupakan hasil usaha penulis, tetapi berkat kerjasama dan bantuan berbagai pihak. Untuk itu dalam kesempatan ini penulis mengucapkan terima kasih, khususnya kepada : (1) Bapak Dwiwanto 
sebagai Direktur PT. MTM dan Staf yang telah memberikan kemudahan data yang dibutuhkan dan kerjasama yang baik dalam menerapkan metode QCC, (2) Mr. Taisuke Nishida sebagai tenaga ahli Production Management dari JICA Jepang dalam Proyek Peningkatan Kerja Logam untuk Industri Penunjang Mesin Konstruksi di Indonesia (20142016), (3) semua pihak yang telah memberikan sumbangan pemikiran dan diskusi yang bermanfaat yang tidak mungkin ditulis satu per satu.

\section{DAFTAR PUSTAKA}

Achadiat Atmawinata, Dkk. 2008. "Kedalaman Struktur Industri Yang Mempunyai Daya Saing Di Pasar Global.” Jakarta.

APO. 2015. Hanbook on Productivity. The Asian Productivity Organization. Tokyo: The Asian Productivity Organization (APO).

Astra. 2010. Buku Pedoman Astra Total Quality Control (ATQC). Jakarta: Astra Indonesia.

Darmawan, Wibiksono. 2004. Riset Bisnis, Panduan Untuk Bisnis Dan Akademis. Bandung: PT. Alphabeta.

Hafid Abdullah, Kuntari A.S. 2012. "Pengendalian Mutu No Good (NG) Tertinggi Produksi Bermasalah Di Industri Pembuat Battery Carbon Dengan Metode QC Seven Tools." Teknologi Bahan Dan Barang Teknik Vol.2 No.2 (ISSN:20894767): 63.

Hafid, Eddy Herjanto. 2015. "Analisis Kendala Penumbuhan Industri Mesin Peralatan Pabrik Nasional." Jurnal Riset Industri Vol. 9 No. (ISSN:1978-5852): 50.

Ishikawa, Kaoru. 2005. How to Operate $Q C$ Circle Activities. Edited by QC Circle Headquarters. Tokyo: JUSE.

Jeffey K. Liker, David Meier. 2007. The Toyota Way Fieldbook. Edited by Esensi. Jakarta: Erlangga.

MIDC. 2012. "Penelitian Kapabilitas Teknologi Manufaktur Di Industri Logam Mesin Untuk Pengembangan Produk Substitusi Impor." Bandung.

Nazir, Mochamad. 2011. Metode Penelitian. Tujuh. Bogor: Galia Indonesia.

. 2014. "Undang-Undang Nomor 3 Tahun 2014 Tentang Perindustrian.” In , 2. Jakarta: Kementerian Perindustrian.

Richard B. Chase, F. Robert Jacobs, Nicholas J.
Aquilano. 2004. Operation Management. USA: Mc. Graw Hill/Irwin.

Riggs, James L. 2007. Production Systems: Planning, Analysis and Control. Singapura: John Wiley \& Sons.

Sambas, Hartono. 2014. "Penerapan Konsep Kaizen Dalam Upaya Menurunkan Cacat Appearance Untuk Xenia-Avanza Proses Painting Di PT. Astra Daihatsu Motor.” In , 1. Jakarta: FT Universitas Muhamadiyah.

Schwab, Klaus. 2017. "The Global Competitiveness Report 2016-2017." Geneva.

Sugiono. 2008. Metode Penelitian Bisnis. Bandung: PT. Alfabeta.

Ueso, Sayoko. 2011. Quality Control Circles in Burkinan Faso: Lessons Leared and Implications for Other Developing Countries. Japan: JICA, National Graduate Institute for Policy Studies (GRIPS).

Wirasasmita, Yuyun. 2013. "Ilmu Dan Seni Kewirausahaan.”, Bab 6, Hal. 2. Bandung: Program Doktor Ilmu Manajemen, UNPAS. 